
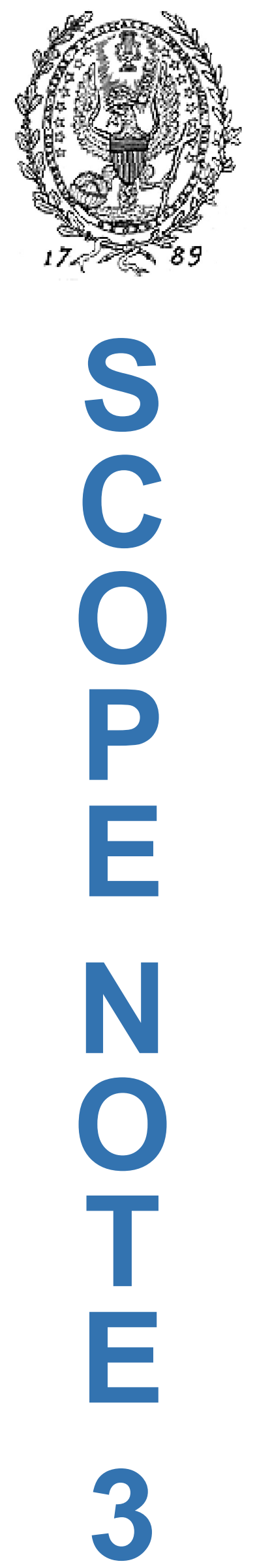

Bioethics Research Library

The Joseph and Rose Kennedy Institute of Ethics

Box 571212, Georgetown University

Washington, DC 20057-1212

202-687-3885; fax: 202-687-8089

bioethics@georgetown.edu

http://bioethics.georgetown.edu

\title{
Ethics Committees in Hospitals
}

\author{
Pat Milmoe McCarrick \\ Revised September, 1992
}

(Literature about hospital ethics committees has grown enormously since Scope Note 3 first appeared. This update provides new information about resources and documents now available while continuing include important earlier sources.)

Hospital ethics committees have taken hold in the United States increasingly since 1983, when the President's Commission for the Study of Ethical Problems in Medicine and Biomedical and Behavioral Research encouraged their creation in its report, DECIDING TO FOREGO LIFE- SUSTAINING TREATMENT (III, 1983, p. 5).

The President's Commission report (pp. 160-64) suggested the following roles for ethics commit-tees: 1) review of treatment decisions made on behalf of incompetent, terminally ill patients; 2) review of medical decisions having ethical implications with the option, in cases of disagreement, to refer cases to a court with proper jurisdiction; 3) provision of social, psychological, spiritual, or other counseling for patients, family members, physicians, or other hospital staff; 4) establishing guidelines regarding treatment or other medical decisions; and 5) sponsoring or conducting educational programs to inform all concerned, including the public, about ethical problems in medicine.

No exact count of these committees is available. According to estimates cited by Donald F. Phillips, managing editor of Hospital Ethics, about two-thirds to three-fourths of hospitals with more than 200 beds have ethics committees, as do about one-third of hospitals under 200 beds. He thinks that about half of the 6,000 hospitals in the United States now have working ethics committees.

Several journal articles and a court decision in the late 1970s influenced their formation. A 1975 journal article by pediatrician Karen Teel (VII A) urged the use of hospital ethics committees to provide for dialogue in individual care situations as an appropriate sharing of responsibility. Another early article suggested that beyond parents and treating physicians, a "disinterested," mixed lay and medical committee could consider cases about defective newborns to improve the 


\section{TABLE OF CONTENTS}

I. Bibliographic Sources.......... 3

II. Journals and Newsletters. . . . . . . 3

III. Reference/Government. ........ . 4

IV. Association Statements........ . . 5

V. Audiovisuals. ...............6 6

VI. Books. .............6 6

VII. Journal Articles

A. Historical Background. . . . . . 7

B. General. ............... 7

C. Legal Aspects. . . . . . . . . . 13

D. Membership Issues. . . . . . . . 15

E. Additional Readings......... 15

ethical decisionmaking process (VII A, Robertson and Fost 1976). Three 1977 discussions in the Hastings Center Report high-lighted this new concept (VII A, Levine; Shannon; Veatch 1977).

The court decision was the March 31, 1976 ruling by the New Jersey Supreme Court in the Karen Quinlan case. The parents of a young woman in a persistent vegetative state had requested that she be taken off a respirator. The court designated a "prognosis" role for the hospital ethics committee and stipulated that the committee must concur that the patient will never return to a "cognitive, sapient state" before the life-support system can be withdrawn (In the Matter of Karen Quinlan, 70 N.J. 10, 355 A.2d 647, cert. denied sub nom. Garger v. New Jersey, 429 U.S. 922 [1976]). Shortly after the Quinlan decision, Massachusetts General Hospital's Clinical Care Committee created an ad hoc subcommittee (a psychiatrist, a legal counsel, an ICU nurse, an oncologist/ internist, a surgeon, and a lay person who had recovered from serious cancer disease) which looked at 15 cases. Based on the subcommittee's success, establishment of a permanent committee to review treatment of the terminally ill was recommended by the critical care committee (VII A, Clinical Care Committee 1976).

In its 1984 Baby Doe rules, the federal government recommended establishment of infant care review committees, which promoted the growth of hospital ethics committees (VII C, Povar 1991). In July 1987 Maryland became the first state to require by law that hospitals establish patient care advisory committees to offer advice about choices available in the care of life-threatening illnesses; this requirement was extended to nursing homes in 1990 [codified as amended at Md. Health-Gen. Code Ann. Sections 19-370 to -374 (1990)] (VII C, Hollinger 1991).

Recently the role for these committees has been noted in the ACCREDITATION MANUAL FOR HOSPITALS, 1992 SUPPLEMENT ( $p$. 10, Patient Rights, Section RI.1.1.6.1) of the Joint Commission on Accreditation of Healthcare Organizations (JCAHO), which states that an "organization should have in place a mechanism for the consideration of ethical issues arising in the care of patients and to provide education to caregivers and patients on ethical issues in health care." In the scoring section, the best score would be made by an organization that has implemented a "mechanism", e.g., an ethics committee, ethics forum, consultation services, or a combination of such services to discuss ethical issues in patient care. Criteria include that all health professionals would participate in the discussion and resolution of ethical issues and be given the educational resources needed to evaluate alternatives, and a means would be in place to educate the patient in the ethical issues surrounding health care. A lesser score is given if the situation is as described, but not all health care givers participate nor are all shifts involved. The worst score is tied to an organization with no process to consider the ethical issues surrounding patient care.

The 1992 JCAHO manual (p. 37) also contains a reference to ethics committees in the section on nursing care: "NC.3.2.1 When the hospital has an ethics committee or other defined structures for addressing ethical issues in patient care, nursing staff members participate." The section notes that nurses are with the patients and those close to them for much of the time during hospitalization, and that nurses need a "defined mechanism" to address the ethical issues that will surely arise. Again, the scoring is best for organizations with the most structure in place.

This Scope Note provides resource information for working ethics committees, as well as for organ-izations in the process of establishing such committees. Material cited is about the committees and their functions; no attempt has been made to include citations to the varied health decisions that these committees might consider. However, sev-eral bibliographic sources and 
journals covering a wide range of issues in bioethics - including ethics committees - are noted. Members of ethics committees are encouraged to contact the National Reference Center for Bioethics Literature for information relevant to their study of ethical issues in medical care.

\section{Bibliographic Sources}

BIOETHICSLINE. The online database is produced by the Bioethics Information Retrieval Project at the Kennedy Institute of Ethics, and is distributed via the MEDLARS network of the National Library of Medicine. It provides citations (about 20 percent with abstracts) from the literature of the health sciences, law, religion, philosophy, social sciences, and the popular media concerned with contemporary medical ethics in health care or biomedical research. Searches on this database may be obtained by telephoning 1-800-MED-ETHX or 1-202-687-3885. BIOETHICSLINE is available in hospital libraries with access to the MEDLARS system, and to those who use the GRATEFUL MED software.

Coutts, Mary Carrington. Basic Resources in Bioethics. Kennedy Institute of Ethics Journal 1(1): 75-90, March 1991. No. 15, Scope Note Series. Washington: National Reference Center for Bioethics Literature, September 1991. 14 p.

This guide to medical ethics literature provides a cross-section of works published since 1980 . Useful listings of sources are provided as well as a selection of books arranged by topic.

Coutts, Mary Carrington. Selected Bibliography on HECs. HEC Forum 3(2): 101-110, 1991 and 4(1): 61-74, 1992.

Coutts, a reference librarian at the National Reference Center for Bioethics Literature, has compiled two bibliographies for HEC Forum surveying literature of interest to hospital ethics committees.

Goldstein, Doris Mueller, ed. SCOPE NOTE SERIES. National Reference Center for Bioethics Literature, Kennedy Institute of Ethics, Georgetown University, Washington, DC 20057-1065.

Scope Notes offer timely information on specific topics of current interest in biomedical ethics. They contain recent information on issues along with relevant bibliographic citations (see list at end).

Huttlinger, Lucinda Fitch, ed. NEW TITLES IN BIOETHICS. National Reference Center for Bioethics Literature, Kennedy Institute of Ethics, Georgetown University, Washington, DC 20057-1065.

The quarterly publication offers a list of new works acquired by the National Reference Center for Bioethics Literature, arranged topic. An annual cumulative edition is available.

Kemmler, Sarah B., and Cornell, Margaret H. Special Bibliography on HECs. HEC Forum 1(5): 275-299, 1989.

Citations in this bibliography include a few articles from the late 1970s, a majority from the mid- 1980s; it ends with work dated 1988.

Walters, LeRoy, and Kahn, Tamar Joy, eds. BIBLIOGRAPHY OF BIOETHICS. Vol. 1-, 1975-. Washington: Kennedy Institute of Ethics, 1984- . (Vols. 1-6. Detroit: Gale, 1975-1980; Vols. 7-9. New York: Free Press/Macmillan, 1981-1983).

The bibliography is published annually and contains the citations added to the BIOETHICSLINE database each year. Each volume has subject, author, and title indexes, and also contains a thesaurus of terms used to search the database.

\section{Journals and Newsletters}

CQ/Cambridge Quarterly of Healthcare Ethics. David C. Thomasma, Thomasine Kushner, and Steve Heilig, eds. Cambridge University Press, 40 West 20th Street, New York, NY 10011-4211. The first issue of this journal, described as an international journal for healthcare ethics committees, appeared in January 1992. It includes papers presented at the first annual Congress of Healthcare Ethics Committees, April 1991, on topics of interest to ethics committees, a discussion of the Patient Self-Determination Act, and several book reviews.

Ethical Currents. Judith Wilson Ross, ed. Center for Healthcare Ethics, St. Joseph Health Systems, 
and California Association of Catholic Hospitals, 440 S. Batavia St., Orange, CA 92668.

The newsletter is published quarterly for members of hospital ethics committees.

Hastings Center Reports. Bette-Jane Crigger, ed. The Hastings Center, 255 Elm Road, Briarcliff Manor, NY 10510.

Begun in June 1971, this popular and respected report is published six times each year and carries work by well-known ethicists about important ethical issues in medicine, the life sciences, and the professions. A special section, Ethics Committees, appeared 19881990 with information of interest to these groups; similar material now appears interspersed throughout the journal.

Health Progress. Judy Cassidy, ed. Catholic Health Association, 4455 Woodson Road, St. Louis, MO 63134-0889.

The journal appears monthly and provides information about general and ethical care issues pertinent to Catholic hospitals.

HEC Forum. Stuart F. Spicker and Judith Wilson Ross, eds. Kluwer, P.O. Box 358, Accord Station, Hingham, MA 02018-0358.

Published six times per year, the HEC (HealthCare Ethics Conunittee) Forum offers articles which provide an interdisciplinary approach to common concerns in health care settings for ethics committee members (physicians, nurses, social workers, risk managers, attorneys, ethicists or laypersons). Begun in 1989, the journal has published articles relevant to ethics committee education, attitudes, perceptions, functions, and involvement in hospital policy. Each issue contains a clinical case presentation.

Hospital Ethics. Donald F. Phillips, ed. American Hospital Association, 840 N. Lake Shore Dr., Chicago, IL 60611.

Topics relevant to the interests of hospital ethics committees are presented in this bimonthly, 16-page publication. Court decisions, current issues, citations to useful literature, and mention of upcoming meetings are included; a recent issue discussed resource allocation, ethics and euthanasia, a survey of ethics committees, care of the AIDS patient, and advance directives.

Journal of Clinical Ethics. G. Edmund Howe, ed. University Publishing Group, 107 E. Church Street, Frederick, MD 21701.

First published in 1990, the quarterly includes reviews, discussions of ethical theory as it relates to clinical practice and case reports, and summary and analysis of legal events and trends. Topics have included living wills, futile treatment, ethics committees consensus, teaching medical ethics, and ethics consultants.

Kennedy Institute of Ethics Journal. Renie Schapiro, ed. Johns Hopkins University Press, 701W. 40th St., Suite 275, Baltimore, MD 212112190.

The quarterly journal presents varied opinions and analysis of critical issues concerned with the social, ethical and publicpolicy aspects of bioethics. Examples of articles useful to ethics committees include a description of an institutional policy for withdrawing or withholding treatment and a work on clinical ethics education. Each issue contains a Scope Note.

\section{Reference/Government}

ENCYCLOPEDIA OF BIOETHICS. Warren T. Reich, ed. New York: Free Press, 1978. Four volumes. Reprinted 1982. Two volumes.

The encyclopedia is under revision, but the first edition remains a comprehensive resource for basic reference articles about most of the important bioethical issues in health care.

U.S. President's Commission for the Study of Ethical Problems in Medicine and Biomedical and Behavioral Research.

The Commission issued reports in the early 1980's on important issues in bioethics; those most useful to hospital ethics committees are listed here. All were originally published by the U. S. Government Printing Office (GPO), Washington, DC, but are out of print and no longer available there. The National Technical Information Service (NTIS), Springfield, VA 22161, 1-703-487-4600, has reprinted these documents; NTIS document numbers are included.

DECIDING TO FOREGO LIFE-SUSTAIN- 
ING TREATMENT: ETHICAL, MEDICAL AND LEGAL ISSUES IN TREATMENT DECISIONS. 1983. 554 p., PB-83236836.

DEFINING DEATH: A REPORT ON THE MEDICAL, LEGAL AND ETHICAL ISSUES IN THE DETERMINATION OF DEATH. 1981. 166 p., PB-83236877.

MAKING HEALTH CARE DECISIONS: THE ETHICAL AND LEGAL IMPLICATIONS OF INFORMED CONSENT IN THE PATIENT-PRACTITIONER RELATIONSHIP. 1982-1983. 3 volumes. Vol. 1 Report, 196 p. PB-83236711; Vol. 2 Appendices, 477 p., PB-83236729; and Vol. 3 Appendices, 251 p., PB-83236737.

SECURING ACCESS TO HEALTH CARE: A REPORT ON THE ETHICAL IMPLICATIONS OF DIFFERENCES IN THE AVAILABILITY OF HEALTH SERVICES. 1983. 3 volumes. Vol. 1 Report, 223 p., PB83236752; Vol. 2 Appendices, 305 p., PB83236760; and Vol. 3 Appendices, 418 p., PB83236778 .

SUMMING UP: FINAL REPORT ON STUDIES OF THE ETHICAL AND LEGAL PROBLEMS IN MEDICINE AND BIOMEDICAL AND BEHAVIORAL RESEARCH. 1983. 137 p., PB-83236810.

\section{Association Statements}

American Academy of Pediatrics. Guidelines for Infant Bioethics Committees. April 1984. 11 p. The Academy encourages the formation of committees to provide educational resources, set guidelines and policies, and review treatment decisions made for infants under two years of age. The guidelines discuss functions, structure, membership, jurisdiction, and procedures.

American Hospital Association. Guidelines: Hospital Committees on Biomedical Ethics. January 1984. 2 p.

The American Hospital Association recognizes ethics committees as suited to directing the educational process, providing a forum, and serving in an advisory capacity to evaluate experience. It indicates that committees should not serve as professional ethics review boards or decision makers (see also, VI, Ross 1986).

American Medical Association, Council on Judicial and Ethical Affairs. Guidelines for Ethics Committees in Health Care Institutions. In: REPORTS, Section 1: 1-4, December 1984. Chicago: American Medical Association, 1984-. The Council report states that ethics committees should be voluntary, educational, and advisory. Such committees consider and assist in resolving "unusual, complicated ethical problems involving issues that affect the care and treatment of patients." The Council recommends that the size not be unwieldy, members be "temperamentally suited" to making recommendations, functions be confined to ethical matters, no laws be violated, recommendations be made in writing but impose no obligations for acceptance on the part of the institution, and that members of ethics committees be prepared to meet on short notice and act in a timely fashion.

American Nurses' Association Committee on Ethics. Guidelines for Nurses' Participation and Leadership in Institutional Ethical Review Process. Kansas City, MO: American Nurses' Association, 1985. 1 p.

The nursing association encourages state nurses' associations to have nurses participate in the development, implementation, and evaluation of ethical review on ethics committees.

International Bioethics Institute, 1722 Mar West, Tiburon, CA 94920-1932. William Atchley, Director.

This California-based group, founded in 1988, was organized to design programs and plan future roles of bioethics committees in health care settings. Its first annual Congress of Healthcare Ethics Committees in April 1991 had over 200 participants from 31 states, the District of Columbia, Canada, Holland and Japan. Discussions indicated that ethics committees continue to be concerned with start-up procedures, purpose, and programs. (Ethics Committees: IBI Conference Takes Organizational Reins in Steering Ethics Committees. Hospital Ethics 7(3): 15, 
May-June 1991.)

\section{Audiovisuals}

A Closer Look at the Institutional Ethics Committee. 1985, VHS, Beta, 3/4", 27 min., color. University of Akron AV Services, Akron, OH 44325, phone 216-972-7811.

A simulated hospital ethics committee meeting opens with a physician presenting a problem case for consideration. A nurse, sociologist, minister, and others present views in an effort to reach the most helpful solution for the patient.

Deception. 1986, VHS, 34 min., color. Fanlight Productions, 47 Halifax St., Boston, MA 02130, phone 617-524-0980.

A physician and a nurse disagree about treating a patient without the patient's consent and present their views to an ethics committee.

\section{Books}

Craig, R. P., et al. ETHICS COMMITTEES: A PRACTICAL APPROACH. St. Louis: Catholic Health Association, 1986. 97 p.

Structure, function, membership, meeting plans, and evaluation guidelines of an ethics committee are presented from the Roman Catholic perspective.

Cranford, Ronald E., and Doudera, A. Edward, eds. INSTITUTIONAL ETHICS COMMITTEES AND HEALTH CARE DECISION MAKING. Ann Arbor: Health Administration Press, 1984. $424 \mathrm{p}$.

The book is based on the proceedings of a 1983 conference of the American Society of Law and Medicine which focused on the development of ethics committees. Roles and functions are described, and over 100 pages of sample guidelines and policies are included.

Culver, Charles M., ed. ETHICS AT THE BEDSIDE. Hanover, NH: Dartmouth College/ University Press of New England, 1990. 214 p. Culver, who is chairman of a hospital ethics committee and consults often on medical cases, writes that the sophistication of technology and the demands of patients are major reasons that ethical dilemmas are becoming more con- spicuous and open. He has gathered a dozen complex cases which he says are typical; they are discussed by experienced ethics consultants.

Fletcher, John C.; Quist, Norman; and Jonsen, Albert R., eds. ETHICS CONSULTATION IN HEALTH CARE. Ann Arbor: Health Administration Press, 1989. 209 p.

Eleven essays discuss the role of the ethics consultant, the ethics consultant in the hospital, values, and legal implications and standards of such consultations.

Gorovitz, Samuel. DRAWING THE LINE: LIFE, DEATH, AND ETHICAL CHOICES IN AN AMERICAN HOSPITAL. New York: Oxford University Press, 1990. 195 p.

Philosopher Gorovitz spent seven weeks at Boston's Beth Israel Hospital examining the ethical dilemmas in health care in a modern hospital. He says that these dilemmas raise questions of how decisions should be made and by whom, particularly "where to draw the line" in care that is justified or unjustified.

Hastings Center. ETHICS COMMITTEES: CORE RESOURCE. [Packet]. In collaboration with the College of Physicians of Philadelphia and the Delaware Valley Ethics Committee Network. Briarcliff Manor, NY: Hastings Center, 1988.

The packet contains a copy of HANDBOOK FOR HOSPITAL ETHICS COMMITTEES by Judith W. Ross, et al., copies of various articles useful to committees, and a bibliography prepared in the fall of 1988 .

Hosford, Bowen. BIOETHICS COMMITTEES: THE HEALTH CARE PROVIDER'S GUIDE. Rockville, MD: Aspen Systems, 1986. 340 p.

This useful history and practical guide describes the early institutional review boards as models for bioethics committees. It offers diverse situations to help the establishment of hospital ethics committees, discusses legal aspects, and offers information for special types of committees concerned with infants, nursing homes, or hospices.

Kelly, Margaret John, and McCarthy, Donald G., eds. ETHICS COMMITTEES: A CHALLENGE FOR CATHOLIC HEALTH CARE. 
St. Louis: Catholic Health Association, 1984. $151 \mathrm{p}$.

An early book on ethics committees, it provides background and suggests possible committee models.

Macklin, Ruth, and Kupfer, Robin B. HOSPITAL ETHICS COMMITTEES: MANUAL FOR A TRAINING PROGRAM. Bronx NY: Albert Einstein College of Medicine, 1988. $95 \mathrm{p}$.

The manual describes a program for hospital ethics committees to train and educate physicians, hospital personnel, and those with no clinical experience, i.e., philosophers or theologians. Sample meeting agendas, policy statements, and other guidelines are offered to assist a new ethics group.

Ross, Judith Wilson, et al. HANDBOOK FOR HOSPITAL ETHICS COMMITTEES. Chicago: American Hospital Publishing, 1986. $164 \mathrm{p}$.

The handbook is comprised of three sections: Ethics and Health Care, Bioethics Committees in Practice, and Legal Issues for Bioethics Committees. It offers guidelines, consultation forms, function and goal statements, and case studies. It is designed for practical use in planning and developing roles for ethics committee members.

Weinstein, Bruce D., ed. ETHICS IN THE HOSPITAL SETTING. Morgantown: West Virginia University Press, 1986. 118 p.

Based on the 1984 West Virginia Conference on Hospital Ethics Committees, the book has three parts: Fundamental Concepts, Clinical Perspectives, and Legal and Operational Considerations.

VII. Journal Articles

\section{A. Historical Background}

Clinical Care Committee. Optimum Care for Hopelessly IIl Patients. New England Journal of Medicine 295(7): 362-364, 12 August 1976.

The report discusses the cases an early ad hoc committee looked at and recommends establishment of a permanent group.

Levine, Carol. Hospital Ethics Committees: A Guarded Prognosis. Hastings Center Report 7(3): 25-27, June 1977.

Levine outlines the functions and problems of ethics committees.

Robertson, John A., and Fost, Norman. Passive Euthanasia of Defective Newborn Infants: Legal Considerations. Journal of Pediatrics 88(5): 883-889, May 1976.

Establishment of a committee is suggested as a means of improving the review process for ethical decision making about defective newborns.

Shannon, Thomas. What Guidance from the Guidelines? Hastings Center Report 7(3): 28-30, June 1977.

Guidelines developed by several committees are discussed by the author.

Teel, Karen. The Physician's Dilemma; A Doctor's View: What the Law Should Be. Baylor Law Review 27: 6-9, 1975.

Dr. Teel's work appears to be the earliest citation suggesting the establishment of hospital ethics committees to review individual cases.

Veatch, Robert M. Hospital Ethics Committees: Is There a Role? Hastings Center Report 7(3): 22-25, June 1977.

The author identifies four different general models of hospital ethics committees and looks at their roles.

\section{B. General}

Agich, George J., and Youngner, Stuart J. For Expert's Only? Access to Hospital Ethics Committees. Hastings Center Report 21(5): 17-25, September-October 1991.

Agich and Youngner question whether patients and their families should have direct access to hospital ethics committees and to what extent they should know about relevant deliberations when case reviews are discussed. They think that ethics consultants offer an opportunity for interaction with patients and families and are 
less threatening than an entire committee review.

Allen, C., and Ross, G. E. The Policy Forum. Hospital Progress 70(3): 48-49, April 1989.

The authors recommend that ethics committees set up subcommittees when specific expertise is needed to draft policy.

Andereck, William S. Development of a Hospital Ethics Committee: Lessons from Five Years of Case Consultations. CQ/Cambridge Quarterly of Healthcare Ethics 1(1): 41-50, Winter 1992.

A committee comprised of only physicians and nurses is described along with the manner in which the group consults when requested. Forty-four consultations and recommendations were received and acted on in a period of about four and a half years. Lessons learned are enumerated.

Annas, George J. Ethics Committees: From Ethical Comfort to Ethical Cover. Hastings Center Report 21(3): 18-21, May-June 1991.

Attorney Annas differentiates institutional ethics committees from institutional review boards (IRBs) since these committees have no standard mission and operate under no governing regulations. He thinks that they should be called a risk management or liability control committee; that the term "ethics" is inappropriate. Lawyers should not be members of these committees, according to Annas, who predicts that if ethics committees make legal pronouncements, medicine is made only more legalistic and impersonal.

Baginski, Y., and Bayley, C. A System of Values: Values Committees Help a System Preserve Its Mission. Health Progress 71 (1): 93-95, JanuaryFebruary 1990.

The authors describe committees established in 1988 to translate Christian values into attitudes and behaviors that could be applied to hospital work.

Barlotta, Flora M., and Scheirton, Linda S. The Role of the Hospital Ethics Committee in Educating Members of the Medical Staff. $H E C$ Forum 1(3): 151-158, 1989.

Ethics committees are urged to find formal educational courses in their area for hospital staffs; organize ethics seminars; make available guidelines or policies in bioethics topics; plan rounds and conferences integrating moral issues and clinical data; establish clerkships; set up brief "brown-bag" sessions; show pertinent audiovisuals; and have bioethical literature available.

Benjamin, Martin. Philosophical Integrity and Policy Development in Bioethics. Journal of Medicine and Philosophy 15(4): 375-389, August 1990.

Benjamin notes that philosophers who accept positions on commissions, task forces, or committees cannot be uncompromisingly critical, but they must use their skills for critical examination without losing their integrity. $\mathrm{He}$ says that compromise and integrity are important in practical ethics and merit more reflection.

Blake, David C. The Hospital Ethics Committee: Health Care's Moral Conscience or White Elephant? Hastings Center Report 22(1): 6-11, January-February 1992.

Blake thinks that American culture does not have a consensus about how to live the ethical life except that such conduct is thought to be a private matter. He urges use of casuistry by hospital ethics committees, that is, case studies that are not theory based, but instead are reviewed to give voice to community sensibility on a particular circumstance and particular conduct to reach a solution to an ethical dilemma.

Boyle, Philip. Business Ethics in Ethics Committees? Hastings Center Report 20(5): 37-38, September-October 1990.

The article discusses whether ethics committees would be co-opted by institutional values if they consider business ethics cases. Boyle thinks that they should consider such cases and uses the example of a physician-owned therapy service.

Brennan, T. A. Ethics Committees and Decisions to Limit Care: The Experience at Massachusetts General Hospital. Journal of the American Medical Association 260(6): 803-807, 12 August 1988.

Physician/lawyer Brennan reviews 73 consult- 
ations about ethical problems concerning terminally ill patients made by the Optimum Care Committee at Massachusetts General from 1974 through 1986. Its members - a nurse, surgeon, internist/lawyer, and psychiatrist/ theologian - did not assume a policy making role nor did they have a role in treatment, he says, but their advice was generally followed and they respected the views of competent patients. Unlike most ethics committees, this committee was consulted only by physicians.

Brock, Dan W. Ethics Committees and Cost Containment. Hastings Center Report 20(2): 29-31, March-April 1990.

The author provides arguments both for and against ethics committee participation in any cost containment discussions, and goes on to say that these committees should not adopt a policy of avoiding involvement, but instead, weigh each case for benefits and risks.

Callahan, Daniel. Ethics Committees and Social Issues: Potentials and Pitfalls. $\mathrm{CQ} / \mathrm{Cambridge}$ Quarterly of Healthcare Ethics 1(1): 5-10, Winter 1992.

Callahan foresees an increased role for ethics committees in hospitals due to increasing bureaucracy, changes in the doctor-patient relationship, narrowing of patient choice, and an expanded role for families. He thinks that the most useful role for ethics committees is one of mediation and conciliation.

Christensen, Kate T. Self-education for Hospital Ethics Committees. HEC Forum 1(6): 333-339, 1989.

Christensen established a curriculum to allow members of her committee to educate themselves, calling such self-education the first and most important task an ethics committee will undertake. She thinks self-education will set the pattern for future actions.

Cohen, Cynthia B. Ethics Committees as Corporate and Public Policy Advocates. Hastings Center Report 20(5): 36-37, September-October 1990.

Predicting that the ethics committee will be the "conscience" of for-profit health care systems, the author describes the role as one of eliciting, developing, and upholding a value structure for the institution. Mature committees will offer experience and knowledge to identify ethical issues in any proposed policy, as well as participate in public discussion of health care.

Cranford, Ronald E., et al. Institutional Ethics Committees: Issues of Confidentiality and Immunity. Law, Medicine \& Health Care 13(2): 52-60, April 1985.

The authors discuss the legal status of ethics committees and set forth basic principles for the committee's place in the hospital structure. Issues of confidentiality and committee immunity are presented.

Doukas, David J. The Design and Use of the Bioethics Consultation Form. Theoretical Medicine 13(1): 5-14, March 1992.

Doukas provides a copy of a bioethics consultation form which he developed as a worksheet to process information and help in analysis. Arranged in outline form, he says it is a useful asset for ethics committee discussions and record keeping.

Fleetwood, Janet E., et al. Giving Answers or Raising Questions? The Problematic Role of Institutional Ethics Committees. Journal of Medical Ethics 15(3): 137-142, September 1989. The authors state that it is naive for ethics committees to attempt to resolve difficult clinical dilemmas in a quick and systematic way and evaluate their strengths and shortcomings. The authors think the medical consultation model is inappropriate and that committees should be valued for the process, not the product of their deliberations.

Furlong, Regina M. The Social Worker's Role on the Institutional Ethics Committee. Social Work in Health Care 11(4): 93-100, Summer 1986.

Suggesting potential roles for social workers in the functions of ethics committees, the author recommends that they should serve because their clinical work offers experience with bioethical issues.

Glaser, John W. Hospital Ethics Committees: One of Many Centers of Responsibility. Theoretical Medicine 10(4): 275-288, December 
1989.

Glaser thinks that hospital ethics committees deserve to flourish, but can pose a problem if all expertise in ethics is seen to reside in a committee. He holds that the hospital's chief officer, the board of trustees, and the senior managers all have ethical responsibilities to human dignity through moral discernment, and discusses guidelines for making ethical decisions just.

Glasser, Gary, et al. The Ethics Committee In the Nursing Home: Results of a National Survey. Journal of the American Geriatrics Society 36(2): 150-156, February 1988.

After surveying 4,504 nursing homes, the authors present information about those with ethics committees including committee composition, function, discussion issues, and problems. They recommend that patients serve as members of a nursing home ethics committee.

Gramelspacher, Gregory P. Institutional Ethics Committees and Case Consultation: Is There a Role? Issues in Law \& Medicine 7(1): 73-82, Summer 1991.

The author reviews the workings of ethics committees and asks various questions that he says go unanswered about the need for these services. If they do begin consultation activities, he urges that they do so only after achieving procedural clarity. On the whole, he thinks that the committees have done more good than harm.

Haddad, A. M. A Source of Support: An Ethics Committee Helps Nurses Do the Right Thing. Health Progress 72(1): 60-63, January-February 1991.

The article describes a nursing bioethics committee established in 1984 to ensure that nurses receive support when they take initiative in ethical decisions.

Iserson, Kenneth V. Strategic Planning for Bioethics Committees and Networks. HEC Forum 3(3): 117-127, 1991.

The author provides suggestions for specific things that ethics committees can do to focus their purpose in an institution, how to decide what groups or individuals will be served, and how their work will be carried out.

Jennings, Bruce. Possibilities of Consensus: Toward Democratic Moral Discourse. Journal of Medicine and Philosophy 16(4): 447-463, August 1991.

The concept of consensus and two models of it are discussed by Jennings who writes that it plays an important role in many influential ethical theories. He thinks that when certain preconditions are met it has a role in ethics decisions; when they are not met, consensus does not emerge and, distinct from mere agreement, there is no moral authority.

LaPuma, John, and Schiedermayer, David L. Ethics Consultation: Skills, Roles, and Training. Annals of Internal Medicine 114(2): 155-160, 15 January 1991. Ethics Consultation. [follow-up Letters] Annals of Internal Medicine 114(9): 807-808, 1 May 1991.

Favoring a clinical model for ethics consultation, the physician authors would require that such a consultant could see the patient promptly. They think that a consultant should be a colleague, negotiator, patient and physician advocate, case manager, and educator. Follow-up letters question whether primary physicians are not the most competent persons involved, whether a new subspecialty of clinical ethics consultant is needed, or if multidisciplinary ethics committees should perform such consultations.

LaPuma, John, and Toulmin, Stephen E. Ethics Consultants and Ethics Committees. Archives of Internal Medicine 149(5): 1109-1112, May 1989. LaPuma and Toulmin describe the services of different ethicists. They think that an ethics consultation service comprising both physicians and nonphysicians is best when the nonphysician is trained to understand the patient's medical condition, since ethics consultants are responsible for patient care and ethics committees are administrative bodies with the major task of advising in creating institutional policy.

Libow, Leslie S., et al. Ethics Rounds at the Nursing Home: An Alternative to an Ethics Committee. Journal of the American Geriatrics Society 40(1): 95-97, January 1992. 
Observing that ethics committees are little used in nursing homes, the authors report on "ethics rounds" at a New York City home for the aged, an open forum or clinical conference with participation of patients and family but without a decisionmaking "aura." Such rounds educate the staff, any of whom may attend a multidisciplinary case presentation, an interview of patient or family, a discussion by the staff, or an overview by an ethicist.

Lo, Bernard. Behind Closed Doors: Promises and Pitfalls of Ethics Committees. New England Journal of Medicine 317(1): 46-50, 2 July 1987.

Lo reviews literature about hospital ethics committees, commenting on goals and procedures, and warns that they operate under conditions ripe for "groupthink." He urges careful consideration, good communication, and creative solutions in setting criteria and evaluating the work of these committees.

Loewy, Erich H. Ethics Consultation and Ethics Committees. HEC Forum 2(6): 351-359, 1990.

Stating that the function of ethics consultants is unclear, he examines what he sees as their complex role. Ethics committees have several functions: promote education about bioethical matters, educate themselves and then help educate staff and community; develop and evaluate policy in bioethical concerns; and assist in making decisions in patient health care. Loewy notes that ethics consultants are frequently members of ethics committees, but do not chair them because a conflict of interest could develop.

MacDonald, Julie; Smith, Shirley A.; and Winter, Robert J. To What Extent Should a Hospital Ethics Committee Be Involved In Hospital Policy Formation? HEC Forum 1(6): 341-350, 1989.

The authors say that unless a committee has experience, an ethics committee can endanger its credibility if it tries to make policy.

Moreno, Jonathan D. Consensus, Contracts, and Committees. Journal of Medicine and Philosophy 16(4): 394-408, August 1991.

Philosopher Moreno looks at classical and contemporary theories and argues that social contract theory places constraints on ethics committees. He discusses consensus and moral authority, as well as committees and moral authority.

Moreno, Jonathan D. What Means This Consensus? Ethics Committees and Philosophic Tradition; Rasinski-Gregory, Dorothy. Consen-sus-Real or Imaginary; Shenk, Ian M. Con-sensus-The Measure of Ethical Permissibility: A Response to Jonathan Moreno. [Article and commentaries]. Journal of Clinical Ethics 1(1): 38-45, Spring 1990.

Moreno describes consensus and offers the views of consensus from virtue ethics and cognitive ethics, from a sociologic view, and finally, from liberal political philosophy. $\mathrm{He}$ concludes that an ethics committee's deliberations combine multidisciplinary knowledge to elevate self-interested negotiation to cooperative inquiry. Rasinski-Gregory thinks ethics commit-tees have to reach a true consensus or they are not doing their intended job. Ian Shenk calls consensus imperfect but reasonable, and says that in a pluralistic society there are often several ethically permissible solutions to most problems.

Mozdzierz, Gerald J.; Reiquam, C. William; and Smith, Linda C. Shaping Access to Hospital Ethics Committees: Some Critical Issues. HEC Forum 1(1): 31-39, 1989.

The authors discuss what they call the "gatekeeping" function of ethics committees: the questions of access and jurisdiction. They describe various attitudes, beliefs, problems, and expectations; the variables of the institution itself will play a part in how the committee works. They urge avoidance of bureaucratic and impersonal rules.

Rasinski-Gregory, Dorothy C.; Miller, Ronald B.; and Kutner, Fredric R. Improving Hospital Ethics Committees: Cross Cultural Concerns and Their Procedural Implications. HEC Forum 1(3): 137-150, 1989.

The authors present a useful set of questions to help assess a patient's background in order to make appropriate decisions. Topics include culture, ethnicity, religion, education and intelligence, work history, and health values. An outline of a values document is appended. 
Rauh, R., and Bushy, A. Biomedical Conflicts in the Heartland: A Systemwide Ethics Committee Serves Rural Facilities. Health Progress 71(2): 80-83, March 1990.

Ten hospital and five nursing home ethics committees in a rural area were set up to provide educational opportunities for members and facilities. The authors tell of the workings of the network since its inception in 1985.

Rawlins, Timothy D., and Bradley, John G. Planning for Hospital Ethics Committees: Meeting the Needs of the Professional Staff. HEC Forum 2(6): 361-374, 1990.

The authors urge ethics committees to have appropriate goals and objectives and provide a sample needs assessment survey, which they used in surveying 74 physicians and 123 nurses.

Robertson, John A. Ethics Committees in Hospitals: Alternative Structures and Responsibilities. Issues in Law and Medicine 7(1): 83-91, Summer 1991.

Robertson provides background and rationale for ethics committees, describing functions, composition, proceedings, and possible public roles.

Ross, Judith Wilson. Case Consultation: The Committee or the Clinical Consultant? HEC Forum 2(5): 289-298, 1990.

The author prefers use of an ethics committee over that of ethics consultants, because ethics committees are part of the hospital community. She thinks they show the ethical concern of the organization as well as a commitment by health professionals to maintain patients' dignity.

Self, Donnie J., and Skeel, Joy D. A Study of the Foundations of Ethical Decision Making of Clinical Medical Ethicists. Theoretical Medicine 12(2): 117-127, June 1991.

The study analyzed data from 52 clinical medical ethicists at 28 health care centers. Most were found to be objectivists, i.e., they thought value judgments were true or false and thus expressions of moral requirements from an external value structure in the world. According to the authors, most of those answering the questionnaire were consistent in their decision making, tending not to hold beliefs incom-patible with their values beliefs.

Sichel, Betty A. Ethics of Caring and the Institutional Ethics Committee. HEC Forum 2(4): 243-255, 1990.

Sichel suggests that a feminine ethic of care should be considered by ethics committees along with standards of justice and utilitarian principles.

Singer, Peter A.; Pellegrino, Edmund D.; and Siegler, Mark. Ethics Committees and Consultants. Journal of Clinical Ethics 1(4): 263-267, Winter 1990.

The physician-ethicist authors think that ethics committees and ethics consultants will continue to grow and develop, and that certification of such consultants is a future consideration. They urge continued education and policy development for committees.

Smith, George P. The Ethics of Ethics Committees. Journal of Contemporary Health Law and Policy 6: 157-170, Spring 1990.

Law professor Smith provides descriptions of models for ethics committees, including an overall hospital ethics program suggested by John C. Fletcher, director of the Center for Biomedical Ethics at the University of Virginia.

Stidham, Gregory L.; Christensen, Kate T.; and Burke, Gerald F. The Role of Patients/Family Members in the Hospital Ethics Committee's Review and Deliberations. HEC Forum 2(1): 3-19, 1990.

Presenting a discussion of the philosophical issues that committees face, the authors synthesize and draw conclusions about each and provide a short table of how much the patient or family might be included in deliberations based on the theories. They recommend that patients and families be invited to initial meetings and be given information about committee discus-sions, allowing some latitude for individual cases.

Swenson, Michael D., and Miller, Ronald B. Ethics Case Review in Health Care Institutions: Committees, Consultants, or Teams? Archives of Internal Medicine 152(4): 694-697, April 1992. 
The authors discuss the advantages and disadvantages in using ethics committees or specialist ethicists and suggest that either might be used in particular situations. They include a third model, a team of three or four persons from different disciplines and with varying expertise. A table of issues that they think are appropriate to each group is included.

Thompson, Mary Ann, and Thompson, J. Milburn. Ethics Committees in Nursing Homes: A Qualitative Research Study. HEC Forum 2(5): 315-327, 1990.

A study of seven nursing home committees indicates that most were self-educated and developed policy, but that none had reviewed cases or conducted individual consultations. The authors look at committee composition, purpose, benefits and liabilities, and obstacles.

Van Allen, Evelyn; Moldow, D. Gay; and Cranford, Ronald E. Evaluating Ethics Committees. Hastings Center Report 19(5): 23-24, SeptemberOctober 1989.

The mission statements of nine ethics committees were reviewed by the authors. Each indicated that the committee was a forum which the authors say is "where persons of various professional disciplines share mutual respect and trust so that various ethical issues and dilemmas can be discussed openly."

Veatch, Robert M. Ethics Committees: Advice and Consent. Hastings Center Report 19(1): 20-21, January-February 1989.

Veatch questions whether taking a case to an ethics committee without the patient's consent violates confidentiality.

Weeks, Lin C., et al. How Can a Hospital Ethics Committee Help? American Journal of Nursing 89(5): 651-652, 654, May 1989.

The activities of a 24-member hospital ethics committee which discussed an average of one or two consultations per month are described by the authors who note that the opinions of the committee are added to the patient's medical record. The group developed an 11 page ethical guideline in the course of its work.

Wikler, Daniel. Institutional Agendas and Ethics Committees. Hastings Center Report
19(5): 21-23, September-October 1989.

Wikler asks the committee to question whether it is an independent agency or part of a manage-ment team, and describes various possible administrative views, supporting the continual monitoring of the function of the committee within the institution.

\section{Legal Aspects}

Cohen, Morton, et al. Everything You Always Wanted to Ask a Lawyer about Ethics Commit-tees. CQ/Cambridge Quarterly of Healthcare Ethics 1(1): 33-39, Winter 1992.

A panel of lawyers answered questions for participants at the April 1991 Congress of Healthcare Ethics Committees. The speakers thought it unlikely that ethics committees would be liable under most circumstances, discussed documenting committee meetings, noted a lack of knowledge of medical ethics by the hospital attorney, and offered legal insights in medical futility and other issues of interest to ethics committees.

Fletcher, John C. The Bioethics Movement and Hospital Ethics Committees. Maryland Law Review 50(3): 859-894, 1991.

Responding to the Susan Wolf analysis (see below), Fletcher asserts that the resolution of ethical issues in clinical settings will always remain a volatile area. He provides both a background and an agenda for the future of the bioethics movement and says that committees are evolutionary. He offers a programmatic approach for their agenda.

Hoffmann, Diane E. Does Legislating Hospital Ethics Committees Make a Difference? A Study of Hospital Ethics Committees In Maryland, the District of Columbia, and Virginia. Law, Medicine and Health Care 19(1-2): 105-119, Spring-Summer 1991.

The University of Maryland's Law and Health Care Program was awarded a grant in 1989 to study the use of hospital ethics committees in Maryland, the District of Columbia, and Virginia. Divided into four phases, the study asked 2,000 hospital staff personnel whom they would consult regarding an unresolved ethical dilemma involving a patient's care. The study collected statistics and provides tables on 
hospital size, committee size and membership, committee longevity, purposes for convening committees, education, types of cases, committee members with most influence, and legal consequences. It concludes that some health care providers may have an inaccurate perception of the role of ethics committees, and recommends more education of hospital staff as to committee functions. Since they found that one-third of those who had used their committee did not find it helpful, those preparing the study support the need for further research into the usefulness of committees and their actual benefit.

Hoffmann, Diane E. Regulating Ethics Committees in Health Care Institutions-Is It Time? Maryland Law Review 50(3): 746-797, 1991.

As part of a 1990 symposium on Hospital Ethics Committees and the Law, law professor Hoffman discusses the background of committees, the decision-making role, and legislating such committees. She concludes that mandating them by law is not warranted, but that use of committees as an alternative to courts deserves consideration.

Hollinger, Paul C. Hospital Ethics Committees and the Law: Introduction. Maryland Law Review 50(3): 742-45, 1991.

Maryland State Senator Hollinger introduces material from the 1990 symposium (see above) describing the Maryland law that went into effect July 1, 1987, requiring hospital ethics committees in that state (for further material from this symposium see also Fletcher, Hoffman, Moreno, Povar, and Wolf in this section).

Moreno, Jonathan D. Institutional Ethics Committees: Proceed with Caution. Maryland Law Review 50(3): 895-903, 1991.

Philosopher-ethicist Moreno points out that "problems of implementing legal requirements into hospital routine are daunting." He holds that ethics committees are poorly understood, bureaucratic problems are often present, and that legislation could undermine their strength.

Murphy, C. A. Searching for Proper Judicial Recognition of Hospital Ethics Committees in
Decisions to Forego Medical Treatment. Golden Gate University Law Review 20(2): 319-344, Summer 1990.

Pointing out that there is inconsistency in the deference given to ethics committees by courts, the author gives an historical background of committees, discusses operational aspects, and provides judicial considerations of hospital ethics committee deliberations and roles. She suggests attempting some uniformity in these committees so that courts believe that they are an impartial body facilitating open communication.

Povar, Gail J. Evaluating Ethics Committees: What Do We Mean by Success? Maryland Law Review 50(3): 904-19, 1991.

Povar, chair of the ethics committee at George Washington University Medical Center, provides background material about ethics committees, and describes her experience with committee work in policymaking, case consultation, and consensus decisions. She foresees that these committees will continue to evolve and try different forms.

White, Bruce, and Gottlieb, Lawrence E. Point and Counterpoint: Should an Institution's Risk Manager/Lawyer Serve as HEC Members? HEC Forum 3(2): 87-93, 1991.

Lawyer White argues that the hospital lawyer and risk manager may be better qualified to assist the committee than a community attorney since they give all their skill and attention to health care matters. The hospital lawyer should not be a member, since unlike the health professionals who are concerned for the rights of a patient, the hospital attorney primarily protects the interests of the institution.

Wolf, Susan M. Ethics Committees and Due Process: Nesting Rights in a Community of Caring. Maryland Law Review 50(3): 798-858, 1991.

Wolf, the Hastings Center law associate, provides a background of ethics committees and questions various "myths" surrounding the committees: that they are in their infancy, that they are purely advisory, or that they are good for patients. She describes two models (consultation and adjudicatory), pointing out that committees can be confused and endanger 
patients. She also discusses the ethical and legal obligations to accord due process.

\section{Membership Issues}

Buehler, David A.; DiVita, Richard M.; and Yium, Jackson Joe. Hospital Ethics Committees: The Hospital Attorney's Role. HEC Forum 1(4): 183-193, 1989.

A discussion about whether or not hospital lawyers should take part in ethics committee deliberations is presented by the authors, who hold the view that it could be a stereotype to narrow their role to only that of the institutional advocate. They suggest that hospital attorneys could be invited as consultants and participantobservers with a teaching role about relevant legal issues.

Helm, Ann, and Mazur, Dennis J. The Role of Attorneys on Hospital Ethics Committees: Potential Influence on Committee Decisionmaking. HEC Forum 1(4): 195-208, 1989.

The authors hold that an attorney can be a valuable member of ethics committees. He or she can educate staff about legal aspects of ethical decisions, be informative about the kinds of cases that the committee can review, and help formulate policy.

Mitchell, Suzanne M., and Swartz, Martha S. Is There a Place for Lawyers on Ethics Committees? A View from the Inside. Hastings Center Report 20(2): 32-33, March-April 1990.

The authors act as in-house hospital counsel and have actively participated in ethics committee work for several years. They think that lawyers bring a valuable perspective to deliberations.

Murphy, Patricia. The Role of the Nurse on Hospital Ethics Committees. Nursing Clinics of North America 24(2): 551-556, June 1989.

Murphy thinks that nurses have expert knowledge in the communication process. They can express questions or views of the patients and families, providing facts which can clarify deliberations of ethics committees. She also recommends that the nurse committee member be able to convene the committee.

Oddi, L. F., and Cassidy, V. R. Participation and
Perception of Nurse Members in the Hospital Ethics Committee. Western Journal of Nursing Research 12(3): 307-317, June 1990.

In a survey of all 255 directors of nursing in acute care hospitals in Illinois, the 148 (58 percent) who replied indicated that about 45 percent of their institutions had ethics committees. Nurses served on all reported committees with two members the average. Profiles of the nurse members, as well as ethics committees profiles, are described.

Rues, Lawrence A., and Weaver, Beth. Membership Issues for Hospital Ethics Committees. HEC Forum 1(3): 127-136, 1989.

The authors describe committee size, composition, selection process, tenure of members, and choice of chairperson. They conclude that the appointment of the members is one of the most critical factors for success of the committee.

Smith, Martin L., and Burleigh, Doug. Pastoral Care Representation on the HEC. HEC Forum 3(5): 269-276, 1991.

Smith and Burleigh recommend that pastoral care representation should be present on hospital ethics committees to consider the patient's spiritual side as well as the bodily ills.

\section{E. Additional Readings}

Abel, P. E. Ethics Committees in Home Health Agencies. Public Health Nursing 7(4): 256-259, December 1990.

Blades, Candace Evans, and Curreri, Michael Paul. Law, Ethics, and Health Care: An Analysis of the Potential Legal Liability of Institutional Ethics Committees. BioLaw: A Legal and Ethical Reporter on Medicine, Health Care, and Bioengineering, Special Sections, 2(33): S317- 326, December 1989.

Brody, Howard. Applied Ethics: Don't Change the Subject. In: CLINICAL ETHICS: THEORY AND PRACTICE. Barry Hoffmaster, Benjamin Freedman, and Gwen Fraser, eds. East Clifton, NJ: Humana Press, 1989, pp. 183-200.

Cannon, Peggy. The Professional Ethics and Practice Committee: A Step Toward the 
Achievement of Excellence. Nursing Administration Quarterly 12(4): 53-56, Summer 1988.

Edens, Myra J., et al. Neonatal Ethics: Development of a Consultative Group. Pediatrics 86(6): 944-949, December 1990.

Ethical Issues in Health Care Institutions. Lesson Three: Hospital Ethics Committees. Radiology Management 13(3): 23-29, Summer 1991.

Ethics Committees Can Be Helpful to Nurses. OR Manager 6(4): 10-12, April 1990.

Feutz-Harter, S. A. Ethics Committees: A Resource for Patient Care Decision-making. Journal of Nursing Administration 21(4): 11-12, 44, April 1991.

Fleischman, Alan R. Parental Responsibility and the Infant Bioethics Committee. Hastings Center Report 20(2): 31-32, March-April 1990.

Hern, H. Gene. A Study of Physician Attitudes and Perceptions of a Hospital Ethics Committee: An Ethics and Human Values Committee Survey. HEC Forum 2(2): 105-125, 1990.

Hollerman, C. E. Membership of Institutional Ethics Committees. Physician Executive 17(3): 34-37, May-June 1991.

Kanoti, George A., and Vinicky, Janicemarie K. The Role and Structure of Hospital Ethics
Committees. In: HEALTH CARE ETHICS: A GUIDE FOR DECISION MAKERS. Gary R. Anderson and Valerie A. Glesnes-Anderson, eds. Rockville, MD: Aspen Publishers, 1987, pp. 293-307.

La Puma, John. Clinical Ethics, Mission, and Vision: Practical Wisdom in Health Care. Hospital and Health Services Administration 35(3): 321-326, Fall 1990.

Llewellyn-Thomas, H. A.; Thiel, E. C.; and Clark, R. M. Patients Versus Surrogates: Whose Opinion Counts on Ethics Review Panels? Clinical Research 37(3): 501-505, September 1989.

Terry, Peter B., and Elliot, M. W. The Pulmonary Physician and the Hospital Ethics Committee. Chest 96(5): 1175-1178, May 1989.

Vaux, Kenneth L., and Savage, T. Initiating and Maintaining an Ethics Committee. Seminars in Oncology Nursing 5(2): 82-88, 1989.

(Scope Note 3, Ethics Committees in Hospitals, was prepared originally by Judith Adams Mistichelli, who revised it in 1984. Pat Milmoe McCarrick, a reference librarian at the National Reference Center, updated the material in 1987 and 1989, and prepared this significantly revised version covering literature published through June 1992.) 


\section{Kennedy Institute of Ethics \\ Georgetown University}

\section{INTENSIVE BIOETHICS COURSE}

Each June the Kennedy Institute of Ethics sponsors a one week Intensive Bioethics Course for persons working in the fields of health, law, education, religion, or social work. Members of hospital ethics committees frequently attend. Participants, who live on the Georgetown University campus, study ethical theory and the application of ethical principles to selected problems in health care and biomedical research. Since the inception of the course in 1974, about 1500 persons from throughout the world have participated in the program, which features lectures followed by small group discussion.

Applications may be obtained from:

Kennedy Institute of Ethics

Georgetown University

Washington, DC 20057 